Int. J. Electrochem. Sci., 15 (2020) $559-566$

\title{
Electrochemical Determination of Ferulic Acid in Pinellia Ternata Based on GOs/MWCNTs Nanocomposite Modified Electrode
}

\author{
Zhi Xia ${ }^{1}, Y u$ Zhang ${ }^{1, *}$, Qianzhu Li ${ }^{1}$, Haijun Du², Guofeng Gui ${ }^{1}$, Gaoyu Zhao ${ }^{1}$ \\ ${ }^{1}$ College of Chemistry and Chemical Engineering, Guizhou University of Engineering Science, Bijie \\ 551700, PR China \\ ${ }^{2}$ College of Chemical Engineering, Guizhou Minzu University, Guiyang 550025, PR China \\ "E-mail: guaiguai3522@126.com
}

doi: $10.20964 / 2020.01 .49$

Received: 9 September 2019 / Accepted: 1 November 2019 / Published: 30 November 2019

The rapid electrochemical determination of ferulic acid (FA) was assiduously scrutinized by cyclic voltammetry (CV) using graphene oxide sheets (GOs) and multi-walled carbon nanotubes (MWCNTs) nanocomposites modified glassy carbon electrode. The synergistic out-come of GOs and MWCNTs resulted in superior electrocatalysis performance. Under optimal conditions, the peak current was proportional to FA concentration in the range of $0.24 \mu \mathrm{M}$ to $32 \mu \mathrm{M}$, and $88 \mu \mathrm{M}$ to $1.23 \mathrm{mM}$, with a relative low detection limit of $0.08 \mu \mathrm{M}$. Besides, it was successfully applied to detect FA in Pinellia ternate with recovery values in the range of $102.8 \%-113.2 \%$, which made it a potential alternative tool for the quantitative detection of FA in pharmaceutical analysis and quality evaluation of traditional Chinese medicine.

Keywords: Ferulic acid; Pinellia ternate; Graphene oxide; Muti-walled carbon nanotubes; Electrochemical determination

\section{FULL TEXT}

(C) 2020 The Authors. Published by ESG (www.electrochemsci.org). This article is an open access article distributed under the terms and conditions of the Creative Commons Attribution license (http://creativecommons.org/licenses/by/4.0/). 